\title{
Psychiatric Co-morbidity and Efficacy of Mirtazapine Treatment in Young Subjects With Chronic or Cyclic Vomiting Syndromes: A Case Series
}

\author{
Murat Coskun $^{1 *}$ and Behiye Alyanak ${ }^{2}$ \\ ${ }^{1}$ Women's and Children's Hospital, Child and Adolescent Psychiatry Clinic, Trabzon, Turkey, ${ }^{2}$ Department of Child and Adolescent Psychiatry, \\ Istanbul Medical Faculty, Istanbul University, Istanbul, Turkey
}

The aim of this case report was to evaluate the psychiatric co-morbidity and efficacy of mirtazapine treatment in young subjects with chronic or cyclic vomiting syndromes. This is a case series of 8 young subjects (age range of 6-16 years, $11.12 \pm$ 3.52 years) who were referred or consulted to child psychiatry department. They were referred or consulted by pediatric gastroenterology or surgery departments for the presence of non-remitting and medically unexplained vomiting. They were investigated for co-morbid psychiatric disorders using a structured psychiatric interview. An open trial of mirtazapine was conducted for the treatment and/or prevention of vomiting. Primary outcome measure was Clinical Global Impression-Improvement scale. Subjects were diagnosed with chronic $(n=5)$ or cyclic $(n=3)$ vomiting syndromes. Duration of vomiting ranged from 6 months to 10 years $(3.5 \pm 3.2$ years). All subjects received multiple psychiatric diagnoses with anxiety disorders being the most frequent. Maximum mirtazapine dosage was 7.5-30 mg/day (16.00 $\pm 6.16 \mathrm{mg} /$ day). Three subjects showed complete remission and 5 subjects showed much to very much improvement in vomiting. Most frequent side effects were increased appetite, weight gain and sedation. Young subjects with chronic or cyclic vomiting may frequently suffer anxiety and/or depressive symptoms or disorders. Mirtazapine could be an effective treatment option for the treatment of vomiting and co-morbid anxiety or depressive disorders in these subjects. More systematic research are needed on this topic.

(J Neurogastroenterol Motil 2011;17:305-311)

Key Words

Anxiety; Child; Familial cyclic vomiting syndrome; Gastrointestinal diseases; Mirtazapine

\section{Introduction}

Childhood functional gastrointestinal disorders (FGIDs) include a variable combination of often age-dependent, chronic or recurrent symptoms not explained by structural or biochemical abnormalities. ${ }^{1,2}$ FGIDs are common both in general and clinical populations. ${ }^{3-5}$ Although they are usually not life threatening, they may persist in the majority of those affected, resulting in significant distress in social, family and academic lives of the sub-

Received: February 16, 2011 Revised: March 29, 2011 Accepted: March 31, 2011

(c) This is an Open Access article distributed under the terms of the Creative Commons Attribution Non-Commercial License (http://creativecommons. org/licenses/by-nc/3.0) which permits unrestricted non-commercial use, distribution, and reproduction in any medium, provided the original work is properly cited.

*Correspondence: Murat Coskun, MD

Kadın Dogum ve Cocuk Hastalıkları Hastanesi, Yenicuma, Trabzon 61030, Turkiye

Tel: +90-506-541-7128, Fax: +90-462-326-5126, E-mail: muratcoskun78@yahoo.com

Financial support: None.

Conflicts of interest: None. 
jects, cost to the health care system and to the individual sufferer, as well as reduced quality of life. , $^{5}$

Functional vomiting (FV) and cyclic vomiting syndrome (CVS) are well known examples of FGIDs among young and adult populations. ${ }^{1,7} \mathrm{FV}$, as defined in adults by the Rome III diagnostic criteria, is vomiting of at least 3 months, which need not to be consecutive, in the preceding year with at least 3 separate vomiting episodes in a week. It is found in the absence of obvious metabolic, structural or psychiatric disorders which could explain the vomiting. ${ }^{7} \mathrm{CVS}$ is defined in adults or children as a dramatic clinical syndrome characterized by intense episodes of vomiting lasting over a period of days with alternating periods of intense quiescence. ${ }^{1,8}$ Because the definition of FV in Rome III classification does not include children, we preferred to use chronic vomiting (without organic causes) instead of FV throughout the text. $^{8}$

There are several lines of evidence that individuals with FGIDs may also frequently suffer from several psychiatric disorders or symptoms. A number of studies with adult subjects reported high prevalence of anxiety disorders and depression in individuals with FGIDs. ${ }^{5,9-13}$ However FGIDs such as chronic vomiting or CVS in children and adolescents remain an understudied area and data regarding psychological characteristics of young subjects with FGIDs are limited in the literature. A recent study reported that children and adolescents with CVS are at high risk for internalizing psychiatric symptoms or disorders such as anxiety or affective symptoms. ${ }^{14}$ Meanwhile there is no clear consensus on the treatment of chronic vomiting or CVS in young subjects. There have been a number of studies reporting the efficacy of several pharmacological agents in the treatment or prophylaxis of CVS in children. ${ }^{8,15-20}$ The present study is case series that aim to report the psychiatric co-morbidity and efficacy of mirtazapine treatment in children and adolescents with chronic vomiting or CVS.

\section{Case Series}

\section{Participants}

This is case series of 8 young subjects who were referred or consulted to child psychiatry department. They were referred or consulted by pediatric gastroenterology or surgery departments for the evaluation of a non-remitting and medically unexplained vomiting. All subjects in this study had vomiting for a long period (up to 10 years) causing serious consequences on physical health and significant distress with impairments in social, family and academic lives. They had been investigated by pediatric gastroenterology, surgery and neurology departments in a faculty hospital but no significant medical cause was detected to explain vomiting and vomiting usually did not respond to several antinausea/antiemetic/prokinetic agents. Before psychiatric referral, all subjects took general physical and neurological examinations, gastrointestinal endoscopies, blood tests; 6 subjects had additional brain imaging and 5 subjects had additional electroencephalogram (EEG).

Vomiting showed no or little improvement with several antinausea/antiemetic/prokinetic agents (such as metoclopramide, cyproheptadine, lansoprazole, antihistamines, trimethobenzamide and other antacids) in 6 subjects, selective serotonin reuptake inhibitors (SSRIs) monotherapy in 3 subjects, and SSRIs plus imipramine or olanzapine combinations in 2 subjects.

\section{Assessments}

Because they were referred or consulted after detailed medical investigations had been done we did not order further medical investigations. Diagnosis of CVS was made according to Rome III classification of FGIDs. ${ }^{1}$ Diagnostic psychiatric interview was conducted using Schedule for Affective Disorders and Schizophrenia for School Age Children-Present and Lifetime Version-Turkish Version (K-SADS-PL-T). ${ }^{21}$ The K-SADS-PL is a semi-structured diagnostic interview designed to assess current and past episodes of Diagnostic Statistical Manual of Mental Disorders-IV (DSM-IV) psychiatric disorders in children and adolescents. Psychometric assessment was conducted using Wechsler Intelligence Scale for Children-Revised (WISC-R).

After diagnostic interviews, an open trial of mirtazapine was conducted using initial dosages of 7.5 or $15 \mathrm{mg} /$ day. All parents were asked for their informed consent before initiation of mirtazapine treatment. The severity of symptoms and efficacy of mirtazapine treatment were assessed with Clinical Global Impressionseverity (CGI-S) and improvement (CGI-I) scales. A side effect checklist was used to ascertain treatment related side effects.

\section{Results}

Subjects were 3 boys and 5 girls with an age range of 6-16 years (11.12 \pm 3.52 years). Duration of vomiting ranged from 6 months to 10 years $(3.5 \pm 3.20$ years $)$. Subjects were diagnosed with chronic vomiting $(\mathrm{n}=5)$ or CVS $(\mathrm{n}=3)$. Clinical characteristics of the subjects is presented in Table.

Life time DSM-IV diagnosis among subjects included; sep- 
aration $(\mathrm{n}=5)$, social $(\mathrm{n}=4)$ and generalized anxiety $(\mathrm{n}=2)$, major depressive $(\mathrm{n}=3)$, dysthymic $(\mathrm{n}=1)$, obsessive- compulsive $(n=3)$, panic $(n=1)$ and attention deficit $(n=3)$ disorders, special phobia $(n=4)$, nocturnal enuresis $(n=2)$, somatoform pain disorder $(n=1)$, agoraphobia $(n=1)$, conversion disorder $(\mathrm{n}=1)$ and chronic motor tics $(\mathrm{n}=1)$. Two subjects had subsendromal generalized and social anxiety disorders. No one among the subjects had self-induced vomiting nor received diagnosis of an eating disorder except for 1 subject (case 5) who had binge eating during the next few days following intense vomiting episode. Three of the subjects were determined to have mild mental retardation upon psychometric evaluation using WISC-R. Regarding significant medical history, one of the subjects (case 5) had musculoskeletal dysplasia and another one (case 2) had congenital cataract that required a series of surgical operations and club foot.

Maximum mirtazapine dosage was 7.5-30 mg/day (16.00 \pm $6.16 \mathrm{mg} /$ day). The duration of mirtazapine treatment was $4-8$ months $(5.25 \pm 1.28$ months $)$ at the time of evaluation for the study. Three subjects showed complete remission of vomiting and 5 subjects showed much to very much improvement on CGI-I scale regarding intensity, frequency and/or number of vomiting per day. Vomiting disappeared or improved within a week in 5 subjects who received diagnosis of chronic vomiting. Mirtazapine was significantly effective in reducing intensity, duration and number of vomiting per day in remaining 3 subjects with CVS. Medication was discontinued in 7 subjects during follow up and vomiting relapsed within 2 to 16 days in all subjects. However vomiting disappeared or improved with readministration of mirtazapine in all of them.

Table. Clinical Characteristics and Treatment Response of the Subjects

\begin{tabular}{|c|c|c|c|c|}
\hline Case & Age (yr)/Sex/DSM-IV diagnosis & Brief description of clinical picture & $\begin{array}{c}\text { Dosage/Duration } \\
\text { of treatment }\end{array}$ & $\begin{array}{l}\text { CGI improvement } \\
\text { in vomiting }\end{array}$ \\
\hline 1 & $12 / \mathrm{M} / \mathrm{SAD}$ and $\mathrm{SP}$ & $\begin{array}{l}\text { 3-10 times vomiting in a day since the age of } 2 \text {. } \\
\text { Two times of acute, severe esophageal bleeding. } \\
\text { Surgical operations failed to reveal any cause or treat } \\
\text { the vomiting. }\end{array}$ & $\begin{array}{l}15 \mathrm{mg} / \mathrm{day} \\
8 \mathrm{mo}\end{array}$ & Complete remission \\
\hline 2 & $\begin{array}{l}\text { 16/F/SAD, GAD, PD, OCD, SoAD, } \\
\text { SP, SPD, AF and ADHDi }\end{array}$ & $\begin{array}{l}\text { 2-5 times of vomiting in a day for the last year. } \\
\text { Sometimes related to feeding and smell of meal. } \\
\text { Non-self induced. No anorexic/bulimic symptoms. }\end{array}$ & $\begin{array}{l}15-30 \mathrm{mg} / \text { day } \\
5 \mathrm{mo}\end{array}$ & Very much improved \\
\hline 3 & $\begin{array}{l}\text { 14/M/MDD, DD, NE, subsyndromal } \\
\text { GAD, SoAD and MMR }\end{array}$ & $\begin{array}{l}\text { 5-10 times of vomiting in a day for the last } 2 \text { years. } \\
\text { Subsequent to the onset of depression. Related to } \\
\text { psychosocial stressors most of the time. }\end{array}$ & $\begin{array}{l}15 \mathrm{mg} / \text { day } \\
4 \mathrm{mo}\end{array}$ & Very much improved \\
\hline 4 & $\begin{array}{l}\text { 11/F/SAD, MDD, SP, ADHDi, SP } \\
\text { and CMT }\end{array}$ & $\begin{array}{l}\text { 5-10 times of vomiting in a day for the last year. } \\
\text { Unrelated to feeding. Started subsequently to the } \\
\text { onset of depression. }\end{array}$ & $\begin{array}{l}15 \mathrm{mg} / \text { day } \\
5 \mathrm{mo}\end{array}$ & Complete remission \\
\hline 5 & $\begin{array}{l}\text { 8/F/SoAD, GAD, OCD, ADHDi and } \\
\text { MMR }\end{array}$ & $\begin{array}{l}\text { 20-30 times of vomiting in a day during the last week } \\
\text { of each month since the age of } 3 \text {. Totally asympto- } \\
\text { matic between episodes. Binge eatings was followed } \\
\text { by vomiting episodes. }\end{array}$ & $\begin{array}{l}15 \mathrm{mg} / \text { day } \\
5 \mathrm{mo}\end{array}$ & Very much improved \\
\hline 6 & 8/F/SAD, SoAD, SP, NE and MMR & $\begin{array}{l}\text { 2-6 times of nausea/vomiting in a day lasting for 2-3 } \\
\text { days with symptom free period of 2-6 weeks since the } \\
\text { age of } 4 \text {. }\end{array}$ & $\begin{array}{l}7.5-15 \mathrm{mg} / \text { day } \\
6 \mathrm{mo}\end{array}$ & Very much improved \\
\hline 7 & 6/M/SAD and SoAD & $\begin{array}{l}\text { 5-6 times of vomiting a day lasting for } 2 \text { or } 3 \text { days for } \\
\text { the last } 2 \text { years. Vomiting was frequently preceded by } \\
\text { abdominal pain, and crying. Symptoms were } \\
\text { relieved by vomiting. }\end{array}$ & $\begin{array}{l}7.5 \mathrm{mg} / \text { day } \\
5 \mathrm{mo}\end{array}$ & Complete remission \\
\hline 8 & $\begin{array}{l}\text { 14/F/MDD, OCD, CD, } \\
\text { subsyndromal GAD and SoAD }\end{array}$ & $\begin{array}{l}\text { Few times of vomiting a day for the last } 6 \text { months. } \\
\text { Frequently preceded/accompanied by nausea and } \\
\text { abdominal pain. Vomiting emerged near the onset of } \\
\text { depression. }\end{array}$ & $\begin{array}{l}15 \mathrm{mg} / \text { day } \\
4 \mathrm{mo}\end{array}$ & Much improved \\
\hline
\end{tabular}

DSM-IV, diagnostic statistical manual of mental disorders-IV; CGI, clinical global impression; SAD, seperation anxiety disorder; SP, special phobia; GAD, generalized anxiety disorder; PD, panic disorder; OCD, obsessive-compulsive disorder; SoAD, social anxiety disorder; SPD, somatoform pain disorder; AF, agoraphobia; ADHDi, attention deficit hyperactivity disorder, inattentive type; MDD, major depressive disorder; DD, dysthymic disorder; NE, nocturnal enuresis; GAD, generalized anxiety disorder; MMR, mild mental retardation; CMT, chronic motor tics; CD, conversion disorder. 
Side effects possibly related to mirtazapine treatment included increased appetite $(\mathrm{n}=5)$, weight gain $(\mathrm{n}=4 ; 2-4 \mathrm{~kg}$, mean $2.75 \pm 0.95 \mathrm{~kg})$, day time sedation $(\mathrm{n}=4)$, headache $(\mathrm{n}=$ $2)$, dry mouth $(n=2)$, urinary frequency $(n=1)$, dizziness $(n=$ 1) and irritability $(n=1)$. Two subjects reported no or very mild side effects. Only 1 subject required dosage reduction due to side effects. Meanwhile increased appetite and weight gain were, in fact, desirable clinical outcome in 3 subjects as they were underweight possibly due to unremitting vomiting.

Three subjects (cases 1, 6 and 7) continued their previously prescribed antiemetic/prokinetic/antacid agents.

\section{Typical Cases 1 and 5}

We present the clinical picture and follow up of 2 sample cases (cases 1 and 5).

\section{Case 1}

A 12 year-old boy presented with vomiting of several times everyday with or without preceding nausea since the age of 2 . He had been investigated extensively in a university hospital for several times and treated with several agents including metoclopramide, lansoprazole, antihistamines, trimethobenzamide and other antiacids. However no significant cause was detected and no improvement was made. He developed acute and severe hematemesis and hematochesia at the ages of 10 and 12. He was admitted and diagnosed with Mallory Weiss Syndrome (characterized by esophageal bleeding caused by a mucosal tear in the esophagus as a result of forceful vomiting or retching). Moreover he had been undergone 2 surgical exploration/operations during the last year without any improvement or significant cause to explain vomiting. He was then consulted to child psychiatry during hospitalization in pediatric gastroenterology clinic. His psychiatric examination revealed separation anxiety disorder and special phobia. His psychometric evaluation revealed a normal intellectual capacity. His previous neurological examination, EEG and brain imaging was all within normal limits. He was given a provisional diagnosis of chronic vomiting and was started on mirtazapine $15 \mathrm{mg} /$ day at bedtime. His vomiting stopped on the third day of treatment and he did not have vomiting for the subsequent 5 days and he was discharged. However the mother discontinued medication for an unknown reason after the discharge and his vomiting reemerged. He was then admitted to pediatric gastroenterology and reconsulted to child psychiatry. He was restarted on mirtazapine $15 \mathrm{mg} /$ day at bedtime and vomiting stopped at the second day of treatment. He did not have vomiting for the subsequent week. He was discharged and referred to child psychiatry with a diagnosis of chronic vomiting. He did not have any vomiting and was able to eat normally during the next 8 months of follow up. He did not report any significant side effects related with mirtazapine treatment except for a weight gain of $3 \mathrm{~kg}$.

\section{Case 5}

An 8 year-old girl was referred by pediatric gastroenterology department due to persistent unexplained vomiting. She reported vomiting of 20-30 times a day during the last week of each month for the last 5 years. It was projectile, non self-induced, and started within the first 3 days of the last week of each month and lasted for 5-7 days. The vomiting disappeared spontaneously and she has been totally symptom free between vomiting episodes. Her repeated endoscopic examinations did not reveal significant findings except for esophagititis which was considered as a consequence of vomiting. Her cranial magnetic resonance imaging and EEG were within normal limits. She has been treated with several agents including lansoprazole, metoclopramide, trimethobenzamide and other antacids for 3 years without any improvement. She had been treated with fluoxetine for her anxiety symptoms for 4 months. Although her anxiety symptoms showed moderate improvement with fluoxetine, no improvement was reported in vomiting episodes.

She was given the diagnosis of musculoskeletal dysplasia at the age of 4 with a current height of $90 \mathrm{~cm}$ and weight of $20 \mathrm{~kg}$. Her psychiatric examination revealed social phobia, generalized anxiety, obsessive-compulsive and attention-deficit disorders and binge eating episodes following vomiting episodes. Her psychometric evaluation revealed mild mental retardation. She was given a diagnosis of CVS and started on mirtazapine $15 \mathrm{mg} / \mathrm{day}$ at bedtime on the 25 th day of the month. Her vomiting episode started on the next day with usual severity and lasted 5 days. However we continued medication and she did not have any vomiting during the next month. The mother reported that this was the first time that she did not have vomiting over the last 5 years. She developed increased appetite and some level of sedation related to mirtazapine treatment and gained $2 \mathrm{~kg}$ within 6 weeks. Therefore we planned to discontinue mirtazapine on the fifth day of the month and to restart it on 20th day to prevent vomiting episode at the end of the month and to avoid side effects. However she developed a milder vomiting episode on the 15 th day of the month which lasted 4 days. This was the first time that vomiting episode occurred on the mid of a month. We restarted mirtazapine 15 $\mathrm{mg} /$ day and continued medication for the next 4 months. The number and intensity of vomiting showed very much improve- 
ment. She had milder vomiting for several times during the episodes. She reported some level of day time sedation and increased appetite related to mirtazapine treatment and gained one more kilogram.

\section{Discussion}

Management of chronic vomiting or CVS may be troublesome for clinicians and should generally involve both pharmacological and non-pharmacological (ie, psychosocial) interventions. A literature review showed that several pharmacological agents, such as valproate, barbiturates, cyproheptadin, amitriptyline, propranolol, erythromycin and L-carnitine have been useful in the management of children with CVS. ${ }^{15-20}$

Mirtazapine is a second generation antidepressant which has both noradrenergic and serotonergic properties with higher antagonistic effect on $5-\mathrm{HT}_{3}$ receptors. ${ }^{22}$ A literature review showed that mirtazapine has been reported as an effective antinausea/antiemetic agent in several groups of adult patients with nausea and vomiting related to depression, ${ }^{23}$ non-mechanical vomiting after gastric bypass, ${ }^{24}$ chemotherapy related nausea and vomiting, ${ }^{25,26}$ SSRIs related nausea, ${ }^{27}$ treatment resistant hyperemesis gravidarum $^{28}$ and postoperative nausea and vomiting. ${ }^{29}$ Moreover, mirtazapine was reported to be effective in reducing nausea and vomiting as rapid as within a few days of treatment. $^{23,24,28}$

The neurotransmitters which are involved in the initiation or maintenance of vomiting have been poorly studied, but dopamine, serotonin, neurokin, histamine and vasopressin have been suggested to be involved in the development of nausea and vomiting, of which $5-\mathrm{HT}_{3}$ and dopamine have been widely accepted as critical neurotransmitters. ${ }^{30}$ It has been suggested that the antagonism of $5-\mathrm{HT}_{3}$ receptor by mirtazapine results in an antiemetic effect which may explain the efficacy of mirtazapine in the treatment of vomiting in adult patients described above. ${ }^{23-29}$

The vomiting and its consequences had a significant impact on medical and mental health, and social, family and academic lives in these subjects. Majority of them needed frequent outpatient or inpatient medical treatments or interventions. We made the diagnosis of chronic vomiting or CVS depending on the medical history, clinical presentation and psychiatric examination. Given the detailed inconclusive medical investigations conducted in a university hospital, we assume that subjects had no significant medical conditions to cause unremitting vomiting.

Mirtazapine was commenced targeting both chronic vomit- ing or CVS and co-morbid anxiety/depressive disorders in these subjects. Our rationale on selecting mirtazapine was (1) the presence of previous reports describing the efficacy of mirtazapine as an effective antinausea/antiemetic agent in several groups of adult patients described above ${ }^{23-29}$ and (2) presence of several studies reporting the efficacy and generally good tolerance of mirtazapine in young subjects with anxiety or depressive disorders. ${ }^{31-34}$

Mirtazapine was significantly effective in the treatment or prophylaxis of chronic vomiting or CVS in these subjects. While 3 subjects showed complete remission, 5 subjects showed much to very much improvement in vomiting. Mirtazapine was generally tolerated well in these subjects. However we discontinued mirtazapine in 7 subjects during follow up and vomiting relapsed, but responded to readministration of medication in all cases. It is important to note that relapse of vomiting after discontinuation may limit the use of mirtazapine as a long term treatment. Rather mirtazapine could be considered for acute treatment of unremitting and disabling vomiting while patients are being prepared for psychosocial interventions as a long term maintenance and preventive intervention.

While there have been several reports that tricyclic antidepressants (TCA) may be useful in the prevention of attacks of cyclic vomiting in children ${ }^{15}$ or adult patients, ${ }^{35,36}$ a previous study reported that antidepressants would not be helpful in the prophylaxis of CVS in children. ${ }^{17}$ However it is important to note that mirtazapine differs from SSRIs or TCAs in terms of pharmacological properties. Mirtazapine has a higher antagonistic effect on serotonergic receptors, particularly $5-\mathrm{HT}_{3}$ receptors. ${ }^{22}$ This is opposite of SSRIs and TCAs that block reuptake pumps for serotonin, norepinephrine or dopamine in varying degrees. ${ }^{37}$ SSRIs are themselves known to cause nausea ${ }^{27,37}$ and they were not effective in the treatment or prevention of vomiting in 5 subjects. It is important to note that SSRIs had been used for primarily anxiety and/or depressive disorders in these subjects for 1 to 5 months. However as we experienced good results with mirtazapine in the treatment of chronic vomiting in few cases, we later switched SSRIs into mirtazapine in these subjects. On the other hand, TCAs do not share the dopamine $\mathrm{D} 2$ or $5-\mathrm{HT}_{3}$ receptor blockades of superior antiemetics. ${ }^{35,37}$ but they may participate in attenuating the nausea/vomiting response through their other receptor actions (blockade of muscarinic cholinergic and $\mathrm{H}_{1}$ histamine receptors). ${ }^{35,37}$ However, a 2 months trial of SSRI/imipramine combination for anxiety disorders and nocturnal enuresis was not effective in reducing vomiting in 1 subject with chronic vomiting (case 2). Therefore it could be suggested that the potent 
antagonistic effect of mirtazapine on $5-\mathrm{HT}_{3}$ receptors may clinically provide us an antidepressant-antianxiety medication with good antinausea/antiemetic effects.

Several psychiatric disorders or psychological stress are widely believed to have a major role in FGIDs in adult and young populations. ${ }^{5,9-14}$ It has been suggested that a link exists between anxiety and the gastrointestinal tract. This is evident in studies examining the effects of stress on gastrointestinal function and also in studies assessing psychopathology in patients with FGIDs which demonstrate a high prevalence of anxiety disorders and depression in these individuals. ${ }^{5,9-14}$ A previous study of children and adolescents with CVS reported that those children are at high risk for internalizing psychiatric symptoms or disorders such as anxiety or affective symptoms. ${ }^{14}$ However this study used unstructured questionnaires and called for the necessity of structured diagnostic interview. The results of our study regarding psychiatric symptoms or disorders are generally consistent with literature. The most frequent life time DSM-IV diagnosis were anxiety disorders $(n=7)$ followed by depressive, obsessive compulsive and attention deficit disorders. If the subjects with subsyndromal, generalized and social anxiety disorders were included, all subjects would have life-time diagnosis of at least 2 anxiety disorders. Meanwhile vomiting emerged at the same time or subsequent to the onset of depression in 3 subjects. This may further suggest a link between depression and vomiting as previously reported in adult patients. ${ }^{9,23}$ However, more researches are needed regarding the relation between anxiety/depression and FGIDs among young population. The presence of mental retardation in 3 and chronic medical problems in 2 subjects may have contributed to the difficulties in coping with emotional, interpersonal and daily life stressors that would predispose them for functional/somatic symptoms.

This study was a descriptive case series suffering from several limitations such as small sample size and uncontrolled study design. In addition, because this study included a small clinical sample of young subjects with chronic vomiting or CVS, clinical characteristics of these subjects may not reflect the general population. However, despite these limitations, this study may contribute to the understanding and management of young subjects with chronic vomiting or CVS. Young subjects with chronic vomiting or CVS may frequently suffer from anxiety and/or depressive disorders. A timely psychiatric consultation may help to identify and treat possible psychiatric disorders and prompt psychopharmacological treatment of unremitting vomiting. Mirtazapine could be a treatment option in these subjects particularly in the presence of anxiety/depressive disorders. Further well-designed, placebo controlled studies with larger samples are needed on this topic.

\section{References}

1. Rasquin A, Di Lorenzo C, Forbes D, et al. Childhood functional gastrointestinal disorders: child/adolescent. Gastroenterology 2006; 130:1527-1537.

2. McOmber MA, Shulman RJ. Pediatric functional gastrointestinal disorders. Nutr Clin Pract 2008;23:268-274.

3. Talley NJ, Zinsmeister AR, Van Dyke C, Melton LJ 3rd. Epidemiology of colonic symptoms and the irritable bowel syndrome. Gastroenterology 1991;101:927-934.

4. Koloski NA, Talley NJ, Boyce PM. Epidemiology and health care seeking of the functional gastrointestinal disorders (FGIDs). A population based study. Am J Gastroenterol 2002;97:2290-2299.

5. Koloski NA, Talley NJ, Boyce PM. Does psychological distress modulate functional gastrointestinal symptoms and health care seeking? A prospective, community cohort study. Am J Gastroenterol 2003;98:789-797.

6. Koloski NA, Talley NJ, Boyce PM. The impact of functional gastrointestinal disorders on quality of life. Am J Gastroenterol 2000; 95:67-71.

7. Tack J, Talley NJ, Camilleri M, et al. Functional gastroduodenal disorders. Gastroenterology 2006;130:1466-1479.

8. Li BU. Cyclic vomiting: the pattern and syndrome paradigm. J Pediatr Gastroenterol Nutr 1995;21(suppl 1):S6-S10.

9. Muraoka M, Mine K, Matsumoto K, Nakai Y, Nakagawa T. Psychogenic vomiting: the relation between patterns of vomiting and psychiatric diagnoses. Gut 1990;31:526-528.

10. Fossey MD, Lydiard RB. Anxiety and the gastrointestinal system. Psychiatr Med 1990;8:175-186.

11. North CS, Hong BA, Alpers DH. Relationship of functional gastrointestinal disorders and psychiatric disorders: implications for treatment. World J Gastroenterol 2007;13:2020-2027.

12. Whitehead WE. Psychosocial aspects of functional gastrointestinal disorders. Gastroenterol Clin North Am 1996;25:21-34.

13. Zhao Y, Ke M, Wang Z, et al. Pathophysiological and psychosocial study in patients with functional vomiting. J Neurogastroenterol Motil 2010;16:274-280.

14. Tarbell S, Li BU. Psychiatric symptoms in children and adolescents with cyclic vomiting syndrome and their parents. Headache 2008;48: 259-266.

15. Andersen JM, Sugerman KS, Lockhart JR, Weinberg WA. Effective prophylactic therapy for cyclic vomiting syndrome in children using amitriptyline or cyproheptadine. Pediatrics 1997;100: 977-981.

16. Hikita $\mathrm{T}$, Kodama $\mathrm{H}$, Nakamoto $\mathrm{N}$, et al. Effective prophylactic therapy for cyclic vomiting syndrome in children using valproate. Brain Dev 2009;31:411-413.

17. Forbes D, Withers G. Prophylactic therapy in cycling vomiting syndrome. J Pediatr Gastroenterol Nutr 1995;21(suppl 1):S57-S59.

18. Gokhale R, Huttenlocher PR, Brady L, Kirschner BS. Use of barbiturates in the treatment of cyclic vomiting during childhood. J 
Pediatr Gastroenterol Nutr 1997;25:64-67.

19. Van Calcar SC, Harding CO, Wolff JA. L-carnitine administration reduces number of episodes in cyclic vomiting syndrome. Clin Pediatr (Phila) 2002;41:171-174.

20. Vanderhoof JA, Young R, Kaufman SS, Ernst L. Treatment of cyclic vomiting in childhood with erythromycin. J Pediatr Gastroenterol Nutr 1995;21(suppl 1):S60-S62.

21. Gökler B, Ünal F, Pehlivantürk F, Kültür EÇ, Akdemir D, Taner Y. Reliability and validity of schedule for affective disorders and schizophrenia for school age children-present and lifetime version-turkish version (K-SADS-PL-T). Turk J Child Adoles Mental Health 2004;11:109-116.

22. Anttila SA, Leinonen EV. A review of the pharmacological and clinical profile of mirtazapine. CNS Drug Rev 2001;7:249-264.

23. Pae CU. Low-dose mirtazapine may be successful treatment option for severe nausea and vomiting. Prog Neuropsychopharmacol Biol Psychiatry 2006;30:1143-1145.

24. Teixeira FV, Novaretti TM, Pilon B, Pereira PG, Breda MF. Mirtazapine (Remeron) as treatment for non-mechanical vomiting after gastric bypass. Obes Surg 2005;15:707-709.

25. Kast RE, Foley KF. Cancer chemotherapy and cachexia: mirtazapine and olanzapine are 5-HT3 antagonists with good antinausea effects. Eur J Cancer Care (Engl) 2007;16:351-354.

26. Thompson DS. Mirtazapine for the treatment of depression and nausea in breast and gynecological oncology. Psychosomatics 2000;41: 356-369.

27. Caldis EV, Gair RD. Mirtazapine for treatment of nausea induced by selective serotonin reuptake inhibitors. Can J Psychiatry 2004;49: 707.

28. Guclu S, Gol M, Dogan E, Saygili U. Mirtazapine use in resistant hyperemesis gravidarum: report of three cases and review of the literature. Arch Gynecol Obstet 2005;272:298-300.
29. Chen CC, Lin CS, Ko YP, Hung YC, Lao HC, Hsu YW. Premedication with mirtazapine reduces preoperative anxiety and postoperative nausea and vomiting. Anesth Analg 2008;106:109113.

30. Minami M, Endo T, Hirafuji M, et al. Pharmacological aspects of anticancer drug-induced emesis with emphasis on serotonin release and vagal nerve activity. Pharmacol Ther 2003;99:149-165.

31. Mrakotsky C, Masek B, Biederman J, et al. Prospective open-label pilot trial of mirtazapine in children andadolescents with social phobia. J Anxiety Disord 2008;22:88-97.

32. Haapasalo-Pesu KM, Vuola T, Lahelma L, Marttunen M. Mirtazapine in the treatment of adolescents with major depression: an open-label, multicenter pilot study. J Child Adolesc Psychopharmacol 2004;14:175-184.

33. Coskun M, Karakoc S, Kircelli F, Mukaddes NM. Effectiveness of mirtazapine in the treatment of inappropriate sexual behaviors in individuals with autistic disorder. J Child Adolesc Psychopharmacol 2009;19:203-206.

34. Coskun M, Ahmetoglu E, Ozturk M. Mirtazapine treatment for comorbid anxiety/depressive disorders in young subjects with attention-deficit hyperactivity disorder: case series. Bull Clin Psychopharmacol 2010;20:246-251.

35. Prakash C, Clouse RE. Cyclic vomiting syndrome in adults: clinical features and response to tricyclic antidepressants. Am J Gastroenterol 1999;94:2855-2860.

36. Namin F, Patel J, Lin Z, et al. Clinical, psychiatric and manometric profile of cyclic vomiting syndrome in adults and response to tricyclic therapy. Neurogastroenterol Motil 2007;19:196-202.

37. Stahl MS. Stahl's essential psychopharmacology: neuroscientific basis and practical applications. 2nd ed. New York: Cambridge University Press 2002:199-245. 